\title{
EFFICIENCY OF AN EARLY INTERVENTION WITH PHYSICAL THERAPY ON AN INFANT WITH CONGENITAL TORTICOLLIS
}

\author{
Rață Marinela ${ }^{1 *}$ \\ Frunzete Georgiana ${ }^{2}$ \\ 1,2 “Vasile Alecsandri” University of Bacău, 157 Calea Mărășești, 600115, Romania
}

Keywords: torticollis, congenital, physical therapy

\begin{abstract}
Congenital torticollis is a musculoskeletal pathology which is observed at or shortly after birth and is caused by the fibrosis or unilateral shortening of the sternocleidomastoid muscle (SCM). Physical therapy is one of the main intervention methods for torticollis and aims at: preventing the occurence of mobility limitation, reestablishing the muscular and neuromuscular balance, stimulating the normal infant development. The study was carried out on a 2-month-old patient diagnosed with congenital torticollis. The intervention program consisted in relaxing and stimulating massage, stretching, posture and facilitating exercises in accordance with the stages of development. Following the results, the initial hypothesis was confirmed, physical therapy managing to eliminate torticollis and facilitate normal neurological development of the infant.
\end{abstract}

\section{Introduction}

Due to a reduced space and aphysiological positions in which the head can be found during the intrauterine life, infants may experience postural deficiencies and congenital torticollis. Congenital torticollis is a musculoskeletal pathology which is observed at or shortly after birth and is caused by the fibrosis or unilateral shortening of the sternocleidomastoid muscle (SCM). There are 3 types of torticollis: postural (due to fetal position), sternocleidomastoid muscle tumor and muscular (which is most common) (Cheng \& Au, 1994).

Torticollis is the third congenital musculoskeletal pathology coming after the hip dislocations and equinovarus foot. The torticollis incidence varies by author and ranges from 0.3 to $1.9 \%$ of newborns. $97 \%$ of all cases of torticollis can be treated conventionally (if it occurs within the first 3 months of life) and only $3 \%$ require surgery (if it occurs after 12 months if head rotation exceeds 300) (Campbell et al, 2012).

\footnotetext{
*E-mail: marinela_rata@hotmail.com
} 
Torticollis occurs more often on the right side, thus the baby's head is in a constant left tilt and right rotation. The sternocleidoimastoidian muscle contracture will result in cervical mobility limitation, muscle tone imbalances, abnormal head posture, facial asymmetry, bone changes etc. All these changes generated by torticolis will lead to slowing the motor acquisition, affecting the balance and defense reactions, failing to maintain horizontality and developing an asymmetrical neck and body musculature (Barcelos, 2014).

Diagnosis is based on medical history and clinical evaluation: neck movement amplitude, ultrasonography for fibrosis and magnetic resonance for tumors (Lal, 1979). Torticollis should not be confused with the nontraumatic rotatory subluxation of the atlantoaxial joint (Grisel syndrome), which is accompanied by pain and has the same tilt and rotation of the head as torticollis or with the Klippel - Fail Syndrome (Angoules et al., 2013).

In the 1970s, it was assumed that the central nervous system would be reponsible for generating torticollis. Nowadays, neuroscientists no longer consider torticollis a problem of the central nervous system and list causes such as: ischemia, infections, traumas during birth and child position during the intrauterine life. (Shim \& Jang, 2007).

\section{Material and methods}

This work started from the hypothesis that an early intervention through physical therapy in infants with torticollis will eliminate specific symptoms and facilitate normal neuromotor development.

The research was conducted in the laboratory of sensory stimulation from the physical therapy rehabilitation facility at "Vasile Alecsandri" University of Bacau.

The research methods used were the following: the theoretical documentation method, the measurement and evaluation method, the observation method, the graphical method, the data recording method and the case study method.

The study was carried out on a patient, A.G, 2 months of age, born at 38 weeks by caesarean section. The Apgar score was 10 . Her parents noticed a tendency to a right tilt at 1 month of age and they started recovery at the age of two months. There was no previous collateral family history and the clinical diagnosis was congenital torticollis.

For evaluation we used: visual examination and palpation, Peabody motor development scale, passive joint mobility, anthropometric measurements, assessment of the muscle tone according to the Ashworth scale.

Functional diagnosis: the head is tilted to the right, rotated to the left and slightly flexed, visible hypertonia of the sternocleidomastoidian and left upper trapeze muscle, slight facial asymmetry, cervical mobility limitation, small signs of occipital plagiocephaly, inability to perform symmetrical head movements, disagreement regarding the child motor development according to the stages of development and biological age. 
The intervention through the physical therapy program consisted in: relaxing massage applied to right SCM and left trapeze muscles, tonifying massage applied to the left SCM and right trapeze muscles, passive mobilization of the cervical spine, posture, stretching on the left SCM and right trapezius muscles, facilitation of the head and trunk rotation using visual and auditory stimuli, stimulating low doll position, stimulating balance reactions etc.

Some of the exercises listed above were also applied by parents at home. Along with these exercises, parents were shown the child's posture positions (both in bed and when held in his arms). The frequency of meetings was 3 per week, lasting about 45 minutes.

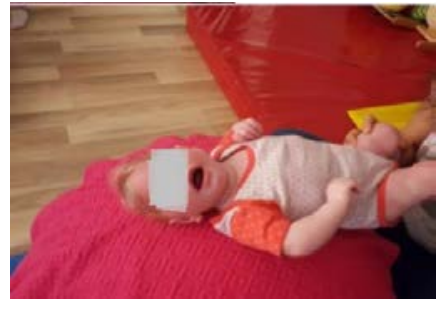

Figure 1. Stimulating

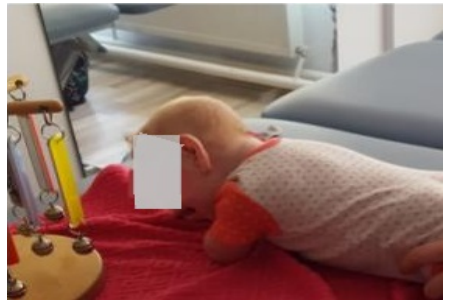

Figure 4. Stimulating

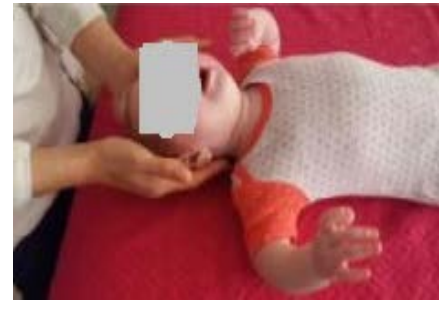

Figure 2. Stretching

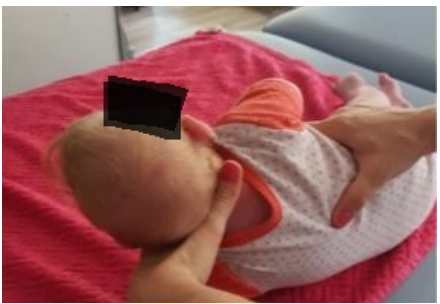

Figure 5. Rolling

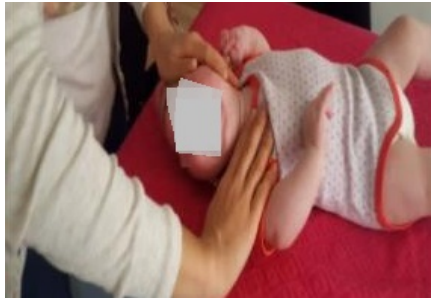

Figure 3. Muscle SCM the rolling

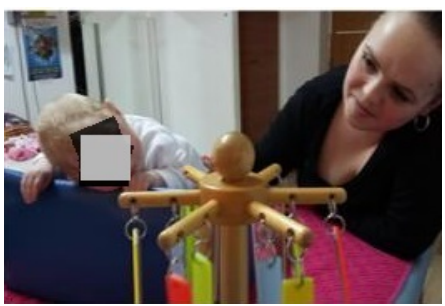

Figure 6. Rolling simulation head extension stimulation performed by mother

\section{Results and discussions}

In order to highlight the evolution of the results we will use charts where we represent the initial and final evaluation values.

Figure 7 presents the evolution on the Peabody scale. After applying the physical therapy program all measurements reached the maximum possible value, namely 8 . Figure 8 shows the evolution of joint amplitudes, which, as on the Peabody scale, reached levels close to the normal. Figure 9 shows the evolution of the anthropometric measurements. 


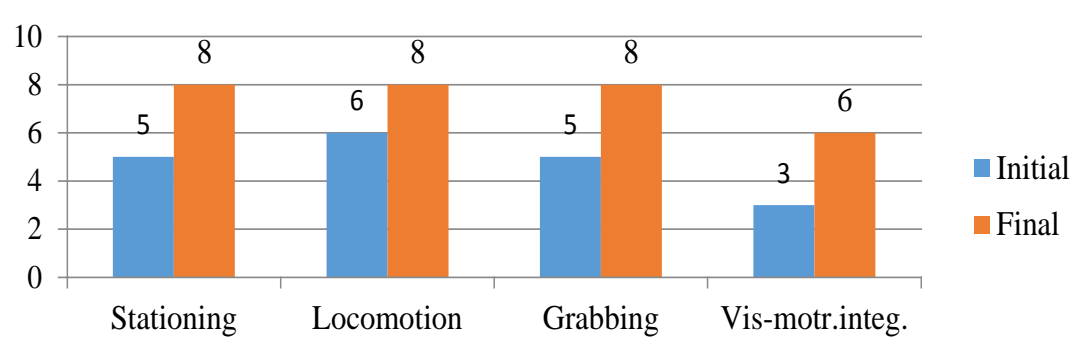

Figure 7. Result evolution on the Peabody scale for 1-2 months

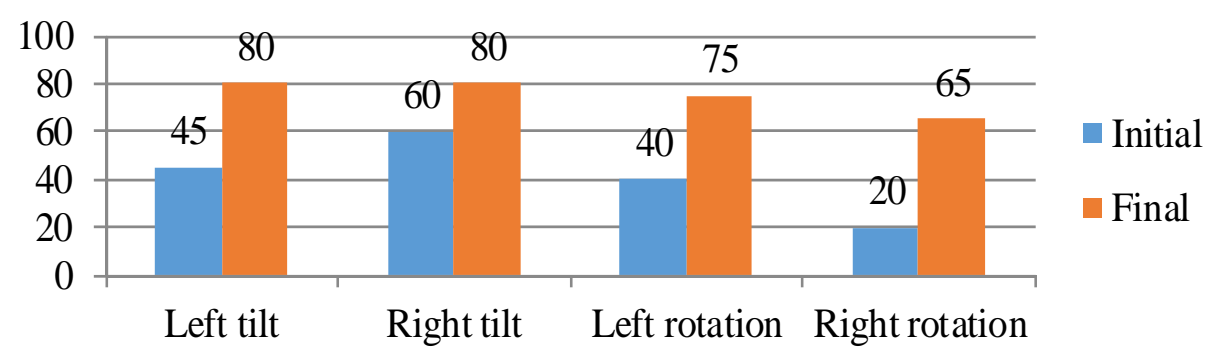

Figure 8. Result evolution for cervical mobility

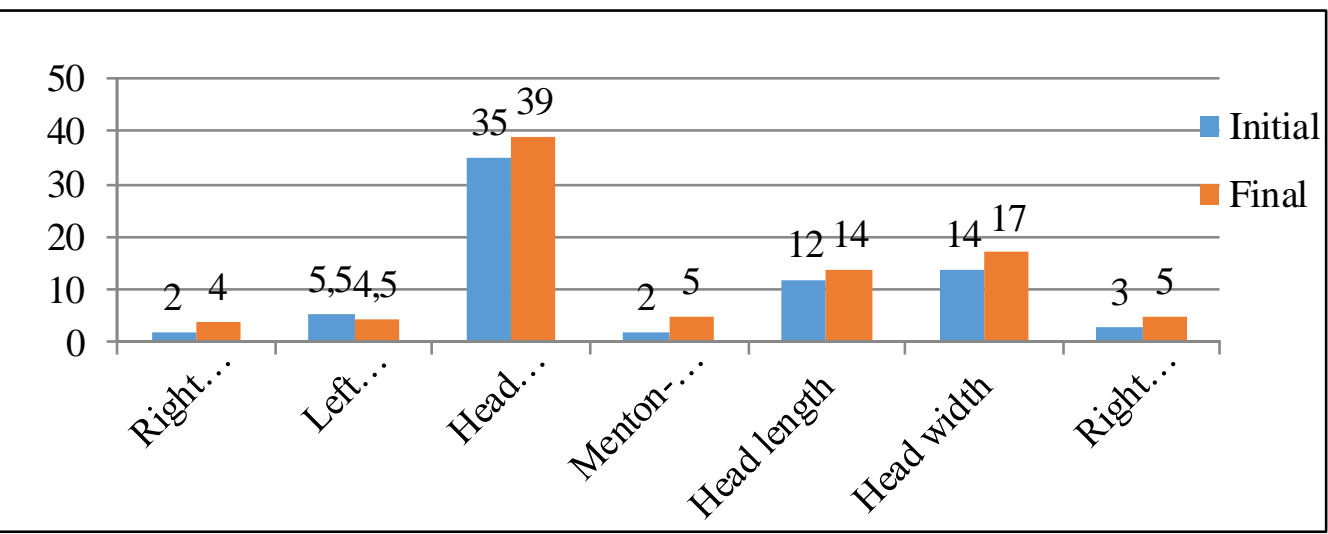

Figure 9. Result evolution of the anthropometric measurements 


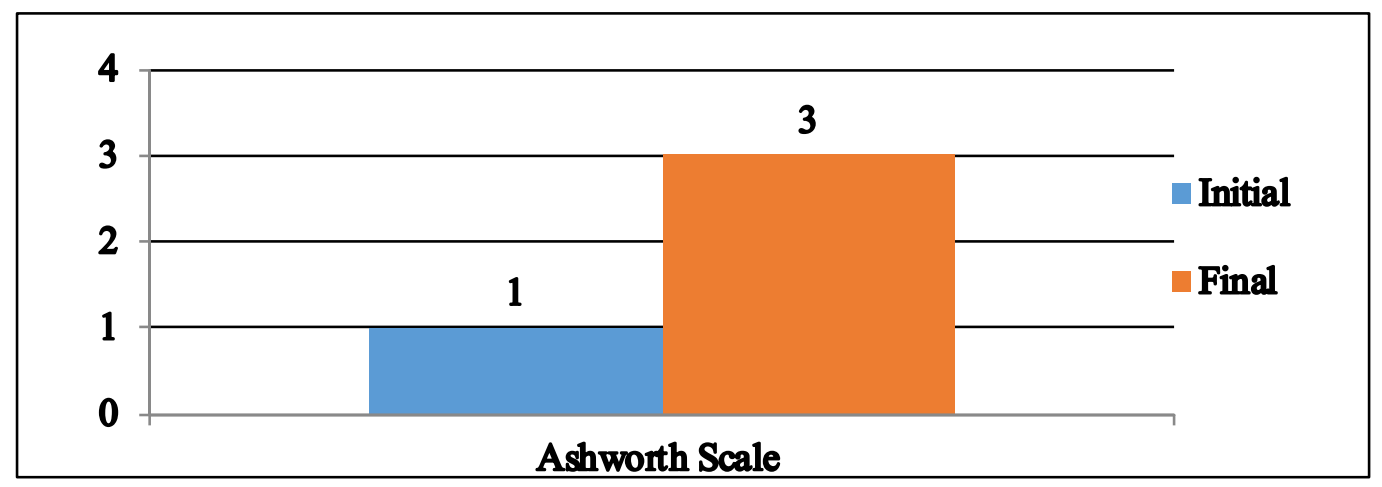

Figure 10. Evolution on the Ashworth Scale

Several anthropometric measurements were made to be objective and to follow closely the development of the subject. Another reason why we made several anthropometric measurements was for a measurement to confirm another. Basically, if the distance between the tragus and the acromion grows, we should automatically have an improvement of the distance between the external occipital protuberance and asterion.

Figure 10 shows the evolution of the muscle tone according to the Ashworth scale, which recorded a positive evolution, but the patient still presents a slight hypertonia of the SCM muscle.

The information provided by the graphics can be interrelated to justify the positive development of the subject. The value improvement on the Peabody scale has a direct connection with the improvement of joint mobility and, even with the Ashworth scale. The three values are interrelated to each other. The anthropometric measurements were designed to measure the subject's progress objectively. Based on them, we can claim the positive evolution development of the plagiocefaly and facial asymmetry. With the help of the charts we can integrate the values obtained from the anthropometric measurements and give them a functional value. More specifically, the improvement in the anthropometric measurements can translate an improvement in the functional abilities of the infant and vice versa.

\section{Conclusions}

- After conducting the research, due to the positive results, we can say that the originally established hypothesis was confirmed.

- An early detection of torticollis is very important because it conditions an early intervention through physical therapy, which is essential for the neurological child development. 
- The exploration and evaluation methods used are objective and directly reflect the results, providing another argument for the importance of physical therapy in children with congenital torticollis.

- The physical therapist-parent relationship is very important and the child development often depends on this aspect, because the parent becomes a member of the interdisciplinary team.

- The child recovered the neuromotor deficit and reached a functional level according to the stages of development.

- The persistence, consistency, dedication and involvement of the interdisciplinary team led to a shortening of the recovery period and an achievement of remarkable results regarding the patient evolution at the psychomotor level.

\section{References}

1. ANGOULES, G., BOUTSIKARI, C., LATANIOTI, P. (2013). Congenital Muscular Torticollis: An Overview, J Gen Pract 1: 105;

2. BARCELOS, A., PATRIOTA, G., NETTO, A. (2014). Nontraumatic Atlantoaxial Rotatory Subluxation: Grisel Syndrome. Case Report and Literature Review, Global Spine Journal, 4:179-186;

3. CAMPBELL, S., PALISANO, R., ORLIN, M. (2012). Physical therapy for children, Elsevier Saunders Publishing House, Missouri, USA;

4. CHENG, J., AU, A. (1994). Infantile Torticolis: a review of 624 cases, Journal of Pediatric Orthopaedics, Volume 14, issue 16;

5. PETRONIC, I., BRDAR, R., CIROVIC, D., et all. (2010). Congenital muscular torticollis in children: distribution, treatment duration and out come. Eur J Phys Rehabil Med 46: 153-157;

6. *** Congenital Muscular Torticollis, (2010), PT connection by Orthopedic \& Sports Physical Therapy Associates, Inc., Vol. 14, Issue 55; 


\title{
EFICIENȚA INTERVENȚIEI TIMPURII PRIN KINETOTERAPIE LA SUGARUL CU TORTICOLIS CONGENITAL
}

\author{
Rață Marinela ${ }^{1}$ \\ Frunzete Georgiana ${ }^{2}$ \\ 1,2Universitatea „Vasile Alecsandri” din Bacău, Calea Mărășești 157, 600115, România
}

Cuvinte cheie: torticolis, congenital, kinetoterapie

\section{Rezumat}

Torticolisul congenital este o patologie musculoscheletală ce se observă la naștere sau imediat după și este cauzată de fibrozarea sau scurtarea unilaterală a mușchiului sternocleidomastoidian (SCM). Kinetoterapia este una din principalele metode de intervenție în cazul tortticolisului și are ca obiective: prevenirea apariției limitărilor de mobilitate, restabilirea echilibrului muscular şi stimularea dezvoltării neuromotorii normale a sugarului. Studiul s-a realizat pe o pacientă în vârstă de 2 luni diagnosticată cu torticolis congenital. Programul de intervenție a constat în masaj relaxant și stimulativ, stretching, posturări și exerciții de facilitate conforme cu stadiile de dezvoltare. În urma rezultatelor obținute, ipoteza inițială a fost confirmată, kinetoterapia reușind să elimine torticolisul și să faciliteze dezvoltarea neuromotorie normală a sugarului.

\section{Introducere}

Datorită spaţiului redus și a pozițiilor afiziologice în care se poate găsi capul în timpul vieții intrauterine, sugarii pot prezenta deficiențe posturale precum torticolisul congenital. Torticolisul congenital este o patologie musculoscheletală ce se observă la naștere sau imediat după și este cauzată de fibrozarea sau scurtarea unilaterală a mușchiului sternocleidomastoidian (SCM). Există 3 tipuri de torticolis: postural (datorită poziției fetale), cu tumoare a muşchiului sternocleidomastoidian și muscular (care este cel mai frecvent) (Cheng \& Au, 1994).

Torticolisul este a 3-a patologie musculoscheletală congenitală ca incidență după luxațiile de șold și piciorul în varus equin. Incidența torticolisului variază în funcție de autor și este cuprinsă între 0,3-1,9\% din nou-născuți. 97\% din totalul cazurilor de torticolis pot fi tratate conservator (dacă se intervine în primele 3 luni de viață) și doar 3\% necesită intervenție chirurgicală (dacă se intervine după 12 luni și dacă rotația capului depășește 30²) (Campbell et al, 2012).

Torticolisul apare mai des pe partea dreaptă, așadar copilul are capul întro permanentă înclinare dreapta și o rotație stânga. Contractura mușchiului sternocleidoimastoidian va determina limitarea mobilității cervicale, dezechilibre ale tonusului muscular, postura anormală a capului, asimetrie facială, modificări osoase etc. Toate aceste modificări generate de torticolis vor duce la încetinirea achizițiilor motorii, la afectarea reacțiilor de echilibru și de 
apărare, la incapacitatea menținerii orizontalității și la o dezvoltarea asimetrică a musculaturii gâtului și trunchiului (Barcelos, 2014).

Diagnosticul se pune pe baza istoricului medical și cu ajutorul evaluării clinice: amplitudinea mișcării gâtului, palpator, ultrasonografie în cazul fibrozelor și rezonanță magnetică nucleară în cazul tumorilor (Lal, 1979). Torticolisul nu trebuie confundat cu subluxația rotatorie nontraumatică a articulaţiei atlantoaxiale (sindromul Grisel), care este insoțită de durere și prezintă aceeași înclinare și rotație a capului ca în cazul torticolisului sau cu sindromul Klippel - Fail (Angoules et al, 2013).

În anii 1970 se presupunea că sistemul nervos central ar fi responsbil de generarea torticolisului. În zile noastre, neurologii nu mai consideră torticolisul o problemă a sistemului nervos central și enumeră cauze precum: ischemia, infecțiile, traumele din timpul nașterii și poziția copilului în timpul vieții intrauterine.

O serie de autori au încercat reducerea tonusului mușchiului SCM prin tehnici de bandajare neuromusculară (kinesiotaping), însă aceaștia nu a înregistrat un rezultat pozitiv. Alte abordări neinvazive au fost $\mathrm{cu}$ ajutorul termoterapiei (în special parafina) (Petronic et al, 2013) și prin injecții cu toxină botulinică (Brenda, 2002), care s-au dovedit a fi mai eficiente decât kinseiotapingul.

Posibilităţile de intervenție în cazul torticolisului sunt multiple. Iniţial se recomandă tratamentul conservator. Acesta constă în exerciţii de tonifiere musculară prin stimularea vizuală și auditivă, stretching pentru mușchii SCM și trapez și educarea părinților în sensul posturării corecte a copilului.

Dacă abordarea prin tratament conservator dă greș, se recomandă interventia chirurgicală. Aceasta se face prin tenotomie subcutanată sau tenotomie deschisă. După intervenția chirurgicală rotația capului se reduce în medie cu $10,8^{0}$, însă aceasta este ultima variantă terapeutică (Shim \& Jang, 2007).

\section{Material și metode}

Această lucrare a pornit de la următoarea ipoteză: intervenția precoce prin kinetoterapie la sugarul cu torticolis va elimina simptomatologia specifică și va facilita dezvoltarea neuromotorie normală.

Cercetarea s-a desfãșurat în laboratorul de stimulare senzorială din baza de recuperare prin kinetoterapie a Universităţii Vasile Alescandri din Bacău.

Metodele de cercetare folosite au fost: metoda documentării teoretice, metoda măsurării și evaluării, metoda observației, metoda grafică, metoda înregistrării datelor, metoda studiului de caz.

Studiul s-a realizat pe o pacientă A.G în vârstă de 2 luni, născută la 38 de săptămâni prin cezariană. Nota obținută la scorul Apgar a fost 10. Părinții au observat tendința de înclinare a capului spre dreapta la 1 lună și au început recuperarea la vârsta de 2 luni. Nu au existat antecedente colaterale în familie, iar diagnosticul clinic a fost de torticolis congenital. 
Pentru evaluare am folosit: examenul vizual și palpator, scala Peabody a dezvoltării motorii, mobilitatea articulară pasivă, măsurători antropometrice, evaluarea tonusului muscular după scala Ashworth.

Diagnostic funcțional: capul este înclinat spre dreapta, rotat spre stânga și uşor flectat, hipertonie marcată a mușchiului sternocleidomastoidian drept și trapez superior stâng, ușoară asimetrie facială, limitarea mobilității cervicale, mici semne de plagiocefalie occipitală, incapacitatea efectuării mișcărilor simetrice la nivelul capului, dezacord în ceea ce privește dezvoltarea motorie a copilului raportat la stadiile de dezvoltare și vârsta biologică.

Programul de intervenție kinetoterapeutic a constat în: masaj relaxant aplicat la nivelul mușchilor SCM drept și trapez stâng, masaj de tonifiere aplicat pe muşchii SCM stâng și trapez drept, mobilizări pasive ale coloanei cervicale, posturări, stretching pe mușchii SCM drept și trapez stâng, facilitări ale rotației capului și trunchiului cu ajutorul stimulilor vizuali și auditivi, stimularea poziției păpușii joase, stimularea reacțiilor de echilibru etc.

O parte din exercițiile enumerate mai sus au fost aplicate și de către părinți, acasă. Alături de aceste exerciții, părinților li s-au arătat poziții de posturare a copilului (atât în pat, cât și atunci când este ținut în brațe). Frecvența ședințelor a fost de 3 pe săptămână, cu o durată de aproximativ 45 de minute.

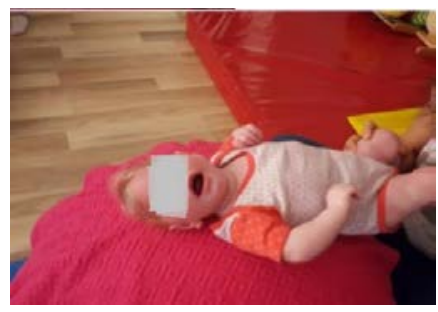

Figura1. Stimulare

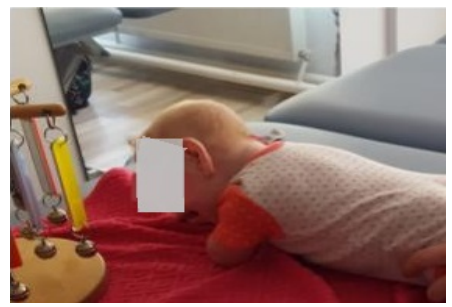

Figura 4. Stimulare

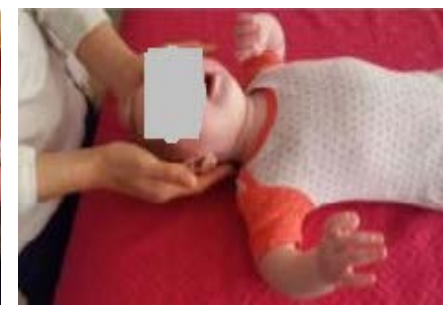

Figura 2. Stretching

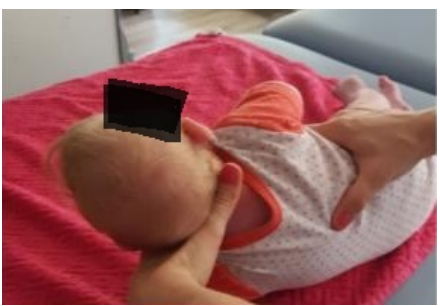

Figura 5. Rostogolire

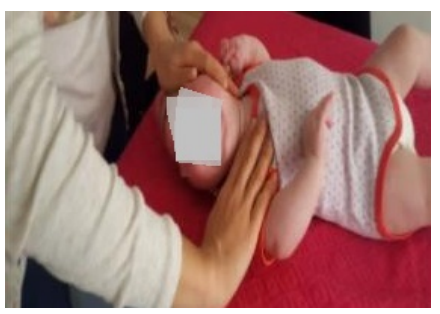

Figura 3. Masaj SCM

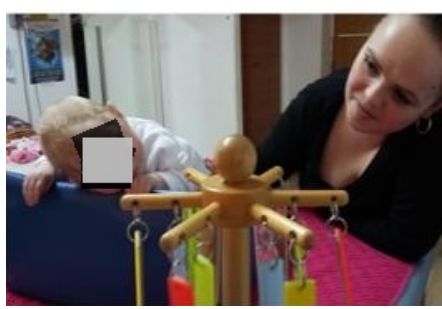

Figura 6. Stimularea extensiei capului rostogolirii intoarcerii de către mamă 


\section{Rezultate și discuții}

Pentru a putea evidenția evoluția rezultatelor subiectului ne vom folosi de grafice unde vom reprezenta valorile evaluărilor inițiale și finale.

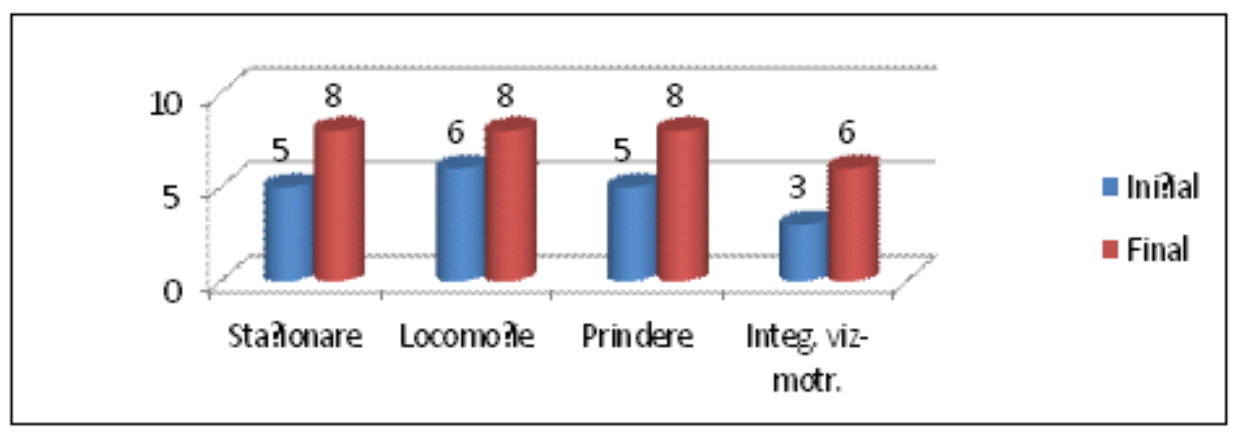

Figura 7. Evoluția rezultatelor pentru scala Peabody 1-2 luni

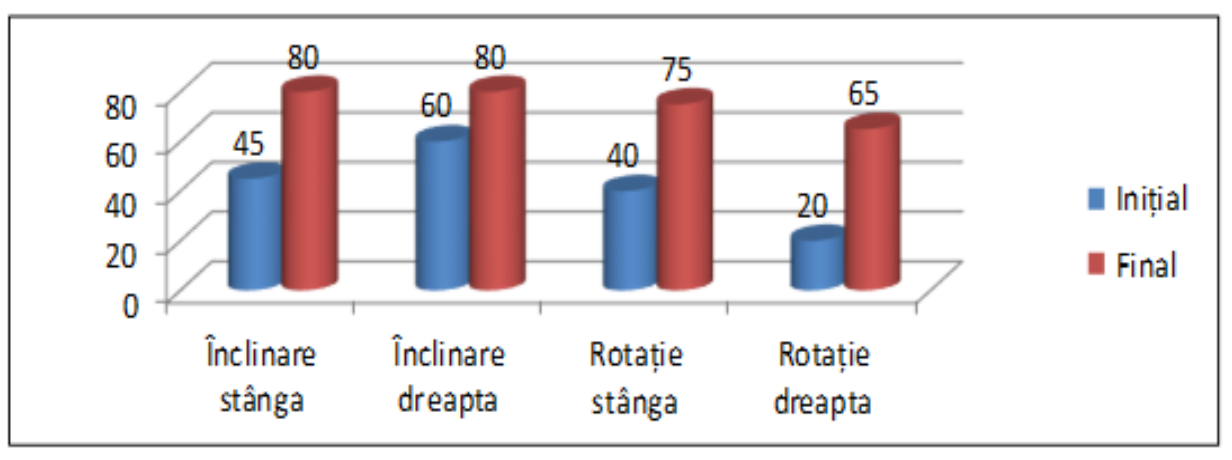

Figura 8. Evoluția rezultatelor pentru mobilitatea cervicală

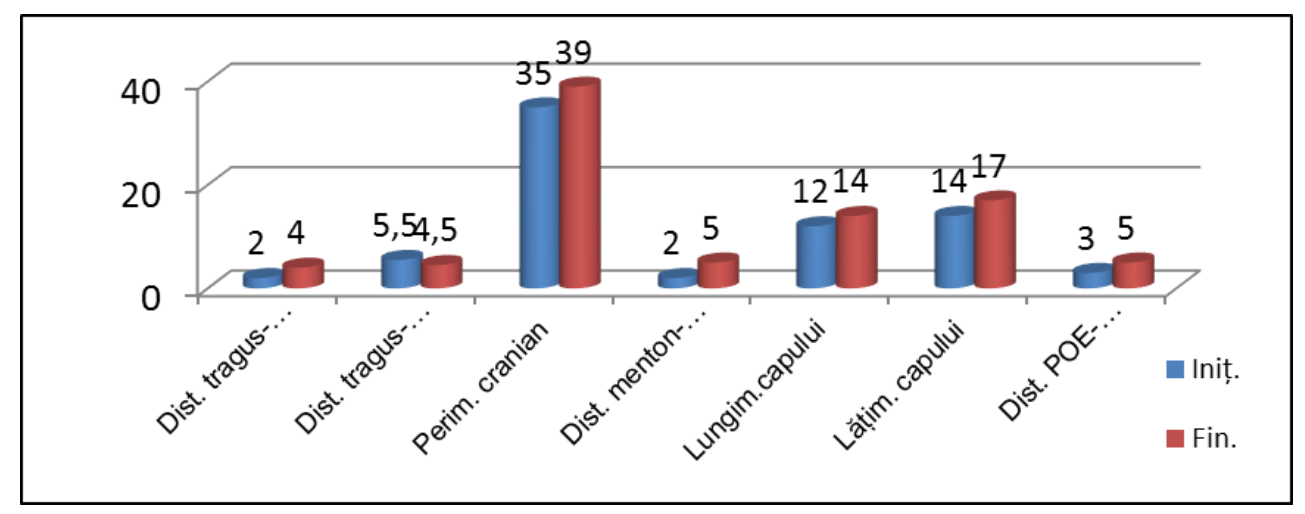

Figura 9. Evoluția rezultatelor măsurătorilor antropometrice 


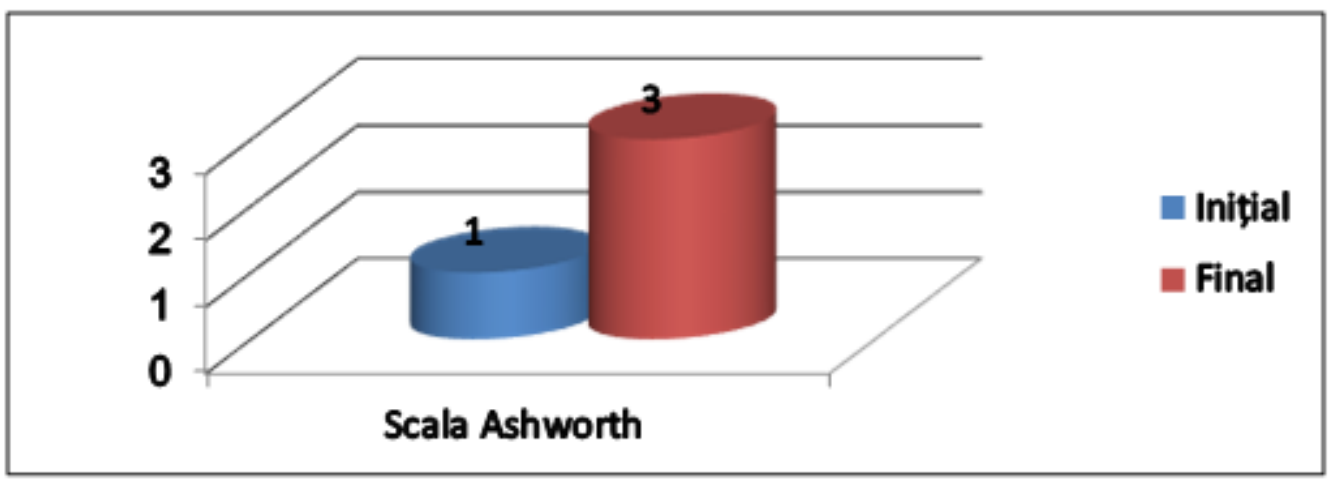

Figura 10. Evoluția scalei Ashworth

Figura 7 prezintă evoluția scalei Peabody. După aplicarea programului de kinetoterapie toate măsurătorile au ajuns la valoarea maximă posibilă, 8 .

Figura 8 prezintă evoluția amplitudinilor articulare, care asemeni scalei Peabody au atins valori apropiate de cele normale.

Figura 9 reprezintă evoluția măsurătorilor antropometrice.

$\mathrm{Au}$ fost făcute mai multe măsurători antropometrice pentru a putea fi obiectivi și pentru a urmări îndeaproape evoluția subiectului.

Un alt motiv pentru care am făcut multe măsurători antropometrice a fost pentru ca o măsurătoare efectuată să o confirme pe alta. Practic, dacă distanţa dintre tragus și acromion a crescut, automat ar trebui să avem și o îmbunătățire a dinstanței dintre protuberanța occipitală externă și asterion.

Figura 10 reprezintă evoluția tonusului muscular conform scalei Ashworth, aceasta a înregistrat o evoluție pozitivă, însă pacienta încă prezintă o mică hipertonie pe mușchiul SCM drept.

Informațiile oferite de grafice pot fi corelate între ele pentru a justifica evoluția pozitivă a subiectului. Îmbunătățirea valorilor scalei Peabody are o legătură directă cu îmbunătăţirea mobilității articulare și, chiar și cu scala Ashworth.

Cele 3 valori sunt în interdependență una față de cealaltă. Măsurătorile antropometrice au avut rolul de a măsura obiectiv evoluția subiectului. $\mathrm{Cu}$ ajutorul acestora putem argumenta evoluția pozitivă a plagiocefaliei și a asimetriei faciale.

Tot cu ajutorul graficelor putem integra valorile obținute la măsurătorile antropometrice și să le dăm o valoare funcțională. Concret, îmbunătățirea măsurătorilor antropometrice se poate traduce prin îmbunătățirea capacităților funcționale a sugarului și viceversa. 


\section{Concluzii}

- În urma cercetării efectuare, ca urmare a rezultatelor pozitive obținute, putem afirma că ipoteza stabilită inițial a fost confirmată;

- Depistarea torticolisului cât mai devreme posibil este foarte importantă deoarece condiţionează intervenția precoce prin kinetoterapie, aspect esențială pentru dezvoltarea neuromotorie a copilului;

- Metodele de explorare și evaluare folosite sunt obiective și reflectă în mod direct rezultatele obținute, ele oferă un alt argument în importanța kinetoterapiei la copilul cu torticolis congenital;

- Relația kinetoterapeut-părinte este foarte importantă și deseori evoluția copilului depinde de acest aspect, deoarece părintele devine un membru al echipei interdisciplinare;

- Copilul a recuperat deficitul neuro-motor și a ajuns la un nivel funcțional conform stadiilor de dezvoltare;

Perseverența, consecvența, dăruirea și implicarea echipei interdisciplinare a condus la scurtarea perioadei de recuperare și la obținerea unor rezultate remarcabile în ceea ce privește evoluția pacientei în plan psiho-motor. 